\title{
The Regulation of 3-Hydroxy-3-Methylglutaryl Coenzyme A Reductase in the Isolated Perfused Rat Liver
}

\author{
Allen D. Cooper \\ From the Department of Medicine, Division of Gastroenterology, Stanford \\ University School of Medicine, Stanford, California 94305
}

\begin{abstract}
A в S T R A C T The effect of perfusion of an isolated rat liver on hepatic 3-hydroxy-3-methylglutaryl coenzyme A reductase was studied. In liver removed during the basal period of the diurnal cycle of enzyme activity, a $227 \pm 41 \%$ increase in enzyme activity occurred after $3 \mathrm{~h}$ of a plasma-free perfusion. This could be prevented by the addition of cycloheximide or pure cholesterol (dispersed with lecithin) to the perfusate. In contrast, the continuous addition of taurocholate or taurochenodeoxycholate, alone or in combination, at a variety of rates did not prevent the increase in enzyme activity. The added bile salts were efficiently extracted from the perfusate and excreted in the bile. The addition of these bile salts to a cholesterol-enriched perfusate did not alter the effect obtained with cholesterol alone.

If the perfusate contained whole serum, the increase incluced by perfusion in the basal period was smaller $(88 \pm 27 \%)$ than with plasma-free perfusate. Again, the major bile salts of the rat failed to prevent the increase in enzyme activity induced by liver perfusion.

If livers were removed and perfused at the height of the diurnal cycle of enzyme activity, the enzyme activity remained high $(2 \pm 10 \%$ increase) rather than decreasing, as occurs in vivo. If cholesterol was added to these perfusions, a $52 \pm 4 \%$ decrease was induced. Bile salt addition induced no decrease. From these results it is concluded that the major bile salts are not direct regulators of hepatic cholesterol synthesis, but pure cholesterol, in the absence of bile salt or lipoprotein, is able to initiate the mechanism that represses hepatic 3-hydroxy-3methylglutaryl coenzyme A reductase.
\end{abstract}

The work was presented in part at the General Session of the 1975 meeting of the American Federation of Clinical Research and published in abstract form (1).

Dr. Cooper is the recipient of National Institutes of Health Clinical Investigator Award AM 00137.

Received for publication 29 . September 1975 and in revised form 2 February 1976.

\section{INTRODUCTION}

Despite intensive investigation, our understanding of the mechanism of the regulation of hepatic cholesterol synthesis remains incomplete. A large number of sterols, lipids, lipoproteins, hormones, and drugs, as well as age, sex, diet, and time of day, have been shown to affect the rate of hepatic cholesterol synthesis (2). It has been firmly established that chronic feeding of bile salts recluces the rate of cholesterol formation by liver (3). However, in vivo there are complex interactions between many of the proposed regulators of cholesterol synthesis (4), and it is often difficult to ascertain whether a substance directly regulates cholesterol synthesis or creates its effect by altering another aspect of cholesterol metabolism. Moreover, the older method for assessing the rate of cholesterol synthesis has been criticized, and several alternative methods have been developed (5-7). Good agreement has been found between measurement of the overall rate of cholesterol synthesis and the activity of 3-hydroxy-3-methylglutaryl coenzyme $\mathrm{A}(\mathrm{HMG} \mathrm{CoA})^{1}$ reductase, the rate-limiting enzyme of cholesterol synthesis (8). Accordingly, measurement of the activity of $\mathrm{HMG}$ CoA reductase in isolated cell preparations has been increasingly utilized to identify the direct regulators of cholesterol synthesis $(9,10)$.

Chenodeoxycholate, a bile salt, is being used successfully to dissolve cholesterol gallstones in man (11). The mechanism for its effect on bile composition is unknown. It may be the result of direct regulation of the activity of hepatic HMG CoA reductase by chenodeoxycholate (12) ; however, the effect may be mediated by bile saltinduced alteration of another aspect of cholesterol metabolism.

\footnotetext{
${ }^{1}$ Abbreziation used in this paper: HMG CoA, 3-hydroxy3-methylglutaryl coenzyme A.
} 
Liersch et al. (13) have previously used the isolated perfused liver to demonstrate that neither cholate nor taurocholate inhibits the rate of hepatic cholesterol synthesis. Further use of this preparation seems an excellent way to resolve the question of whether all bile salts, taurochenodeoxycholate alone, or only cholesterol is the sterol component of bile that primarily regulates the rate of hepatic cholesterol synthesis. Accordingly, we have studied the regulation of $\mathrm{HMG}$ CoA reductase in the isolated perfused liver (1).

\section{METHODS}

Matcrials. Cholesterol was purchased from Calbiochem (San Diego, Calif.) and recrystalized twice from hot glacial acetic acid. No impurities were detected by thin layer chromatography (silica gel $\mathrm{H}$ with benzene: ethyl acetate $(1: 1$, vol: vol)) and by gas-liquid chromatography (1\% XE 60 on Gas-Chrom Q [Applied Science Laboratories, Inc., State College, $\mathrm{Pa}$.] at $210^{\circ} \mathrm{C}$ ). Taurocholate and taurochenodeoxycholate were purchased from Calbiochem and recrystalized by the method of Pope (14). Pure L- $\alpha$-lecithin was purchased from Grand Island Biological Co. (Grand Island, N. Y.), radioactive materials from New England Nuclear (Boston, Mass.), and Mylar-backed silica gel G chromatography sheets from Eastman Kodak Co. (Rochester, N.Y.). $\left[{ }^{14} \mathrm{C}\right] \mathrm{HMG}$ CoA was synthesized by the method of Goldfarb and Pitot (15).

Animals. Male Sprague-Dawley rats, $160-200 \mathrm{~g}$, were used as liver donors for all perfusions. Retired male Sprague-Dawley breeder rats were used as blood donors. The rats were fed Berkeley Diet rat and mouse food (Feedstuff Processing Company, San Francisco, Calif.) ad lib and were housed in windowless rooms illuminated from 7 a.m. to 7 p.m. (normal cycle) or from 4 p.m. to 4 a.m. (reversed cycle). To insure that their diurnal rhythms had adapted, animals were kept in the latter room for at least 10 days before being utilized.

Liver perfusion. After pentobarbital anesthesia, liver perfusion was performed in situ by the method of Mortimer (16). The portal blood flow was interrupted at most for a few seconds during the preparation of the organ. Oxygenation was accomplished with a Silastic coil (Dow Corning Corporation, Midland, Mich.), as described by Hamilton et al. (17), and tubing for the entire apparatus was discarded after each perfusion to prevent bacterial contamination.

Two types of perfusate were used: plasma-free perfusate was composed of $22 \%$ washed aged human red cells in

TABLE I

Perfusate $\mathrm{pH}$ and $\mathrm{PO}_{2}$ in Isolated Perfused Liver

\begin{tabular}{ccc}
\hline Time & $\mathrm{pH}$ & $\mathrm{Po}_{2}$ \\
\hline $1 \mathrm{~h}$ in & $7.38 \pm 0.04$ & $423 \pm 59$ \\
out & $7.23 \pm 0.04$ & $26 \pm 5$ \\
$3 \mathrm{~h}$ in & $7.29 \pm 0.07$ & $385 \pm 62$ \\
out & $7.19 \pm 0.03$ & $23 \pm 4$ \\
\hline
\end{tabular}

Perfusate samples were removed just before (in) or just after (out) passage through the liver and $\mathrm{pH}$ and $\mathrm{Po}_{2}$ were determined on a Corning model 165 blood gas analyzer (Corning Scientific Instruments, Medfield, Mass.). Mean $\pm \operatorname{SE}(n=4)$.
Krebs-Ringer bicarbonate buffer containing $3 \mathrm{~g} / 100 \mathrm{ml}$ bovine serum albumin, Cohn fraction V (Sigma Chemical Co., St. Louis, Mo.) and $100 \mathrm{mg} / 100 \mathrm{ml}$ glucose. A series of experiments revealed no difference in enzyme response when fatty acid-poor albumin was used or when fresh, washed rat red blood cells were used instead of human red blood cells. Hemolysis with this perfusate was $1-2 \%$. Rat blood perfusate was composed of heparinized whole rat blood diluted (1:1, vol: vol) with Krebs-Ringer bicarbonate buffer. Hemolysis with this perfusate was less than $1 \%$. Perfusates were warmed to $37^{\circ} \mathrm{C}$ and $\mathrm{pH}$ was adjusted to 7.4 . The perfusate was circulated at the rate of $1.1 \mathrm{ml} / \mathrm{min}$ per $\mathrm{g}$ liver. Perfusate was equilibrated with $95 \% \mathrm{O}_{2}$ and $5 \% \quad \mathrm{CO}_{2}$ before and at the start of perfusion. This was changed to $100 \% \mathrm{O}_{2}$ when perfusion was established. As shown in Table I, this resulted in excellent maintenance of perfusate $\mathrm{pH}$ and $\mathrm{Po}_{2}$. Viability of the liver was judged by color, ability to extract $\mathrm{O}_{2}$, and absence of gross perfusate loss.

HMG CoA reductase determination. With a PotterElvehjem homogenizer with a Teflon pestle, liver was homogenized with 4 vol of ice-cold buffer $(0.04 \mathrm{M}$ potassium phosphate, $0.1 \mathrm{M}$ sucrose, $0.05 \mathrm{M} \mathrm{KCl}$, and $0.02 \mathrm{M} \mathrm{Na}$ EDTA, $\mathrm{pH}$ 7.2). The homogenate was centrifuged twice at $12,000 \mathrm{~g}$ for $15 \mathrm{~min}$ and the supernate was centrifuged at $105,000 \mathrm{~g}$ for $1 \mathrm{~h}$. The resultant microsomal pellet was resuspended in the buffer described above and immediately assayed for $\mathrm{HMG} \mathrm{CoA}$ reductase. HMG CoA reductase activity was determined by a modification of the method of Goldfarb and Pitot (15). The assay was performed in a total volume of $1 \mathrm{ml}$ of the buffer containing $2 \mu \mathrm{mol}$ NADP ; $10 \mu \mathrm{mol}$ glucose-6-phosphate; $1.7 \mathrm{U}$ glucose 6 phosphate dehydrogenase; $70 \mu \mathrm{mol} \mathrm{NaCl} ; 10 \mu \mathrm{mol}$ dithiothreitol; and $0.5-1.5 \mathrm{mg}$ of microsomal protein. After a 5min preincubation at $37^{\circ} \mathrm{C}, 300 \mathrm{nmol}$ of $\mathrm{D}, \mathrm{L}-\left[3-{ }^{14} \mathrm{C}\right] \mathrm{HMG}$ $\mathrm{CoA}$ (sp act $0.208 \mu \mathrm{Ci} / \mu \mathrm{mol}$ ) was added to initiate the reaction. The incubation was terminated by addition of 0.1 $\mathrm{ml} 10 \mathrm{M} \mathrm{NaOH} 15 \mathrm{~min}$ later. $0.25 \mathrm{ml}$ concentrated $\mathrm{HCl}$ and 20 $\mu \mathrm{mol}$ of $\left[{ }^{3} \mathrm{H}\right]$ mevalonate (sp act $1 \mathrm{nCi} / \mu \mathrm{mol}$ ), which served as an internal standard, were added. This was allowed to stand overnight to insure complete lactonization of the mevalonate. After the addition of sodium sulfate, the mevalonolactone was extracted three times with $7 \mathrm{ml}$ of anhydrous ether; the ether was evaporated and the residue dissolved in $0.2 \mathrm{ml}$ acetone. $\mathrm{HMG}$ and mevalonolactone were separated by thin layer chromatography on silical gel G with acetone: benzene $(1: 1, \mathrm{vol}: \mathrm{vol})$. The mevalonate streak was visualized with ultraviolet light and scraped into a vial. ${ }^{3} \mathrm{H}$ and ${ }^{14} \mathrm{C}$ activity were determined by liquid scintillation counting in Bray's solution. The efficiency of the extraction was determined from the amount of ${ }^{3} \mathrm{H}$ recovered, and the total amount of $\left[{ }^{14} \mathrm{C}\right]$ mevalonate formed was then calculated. By this method, mevalonate formation was linear with addition of $0.1-4 \mathrm{mg}$ of protein and for $50 \mathrm{~min}$. The apparent $K_{m}$ was $62.0 \mu \mathrm{M}$. This is comparable to that reported by others $(18)$.

Experimental design. Uptake and excretion of bile salt was studied by continuously adding radiolabeled bile salt (sp act $0.15 \mathrm{nCi} / \mu \mathrm{mol}$ ) to the perfusate and removing samples of perfusate from a three-way stopcock attached just proximal to the portal vein cannula (inflow) and from the hepatic vein cannula (outflow). Perfusate samples were centrifuged to remove red blood cells. Methanol was added to the supernate $(2: 1, \mathrm{vol}: \mathrm{vol})$ and the precipitated protein removed by centrifugation. A sample of the supernate was dissolved in Aquasol (New England Nuclear) for liquid scintillation counting. Bile was collected in calibrated test tubes through a PE 10 polyethylene cannula (Clay 
Adams, Div. of Becton, Dickinson \& Co., Parsippany, N. J.) inserted in the common bile duct and $0.02 \mathrm{ml}$ was added to Aquasol for scintillation counting.

In experiments to assess change of hepatic HMG CoA reductase activity, the caudate lobe of the liver was removed at the start of a perfusion and the HMG CoA reductase activity compared with that from a sample of the same liver removed after perfusion.

Because the report of Barth et al. (19) suggested that regional differences in cholesterol synthesis are found after liver perfusion, HMG $\mathrm{COA}$ reductase activity was assayed in multiple sections of the same liver. In unperfused livers the $\mathrm{SE}$ was $5 \pm 2 \%$ of the mean and in perfused livers the $\mathrm{SE}$ was $9 \pm 2 \%$ of the mean. Since this degree of variation is not sufficient to affect the results, multiple liver samples were not assayed routinely.

Chemical methods. Cholesterol-phospholipid liposomes were prepared by dissolving cholesterol and phospholipid in chloroform, evaporating the chloroform, adding $0.9 \% \mathrm{NaCl}$, submerging the solution in ice, and sonicating with a Branson sonifier (Branson Instruments Co., Stamford, Conn.) for four periods of $2 \mathrm{~min}$ each (20). The resultant suspension was centrifuged at $30,000 \mathrm{~g}$ for $30 \mathrm{~min}$ and the supernate used. Lipids were extracted from liver perfusate or homogenate by the method of Folch et al. (21). Cholesterol was measured by the method of Zlatkis et al. (22), and protein was measured by the method of Lowry et al. (23). Aspartate amino transferase activity was estimated with a serum glutamic oxaloacetic transaminase Stat Pak (Calbiochem). Statistical significance of results was determined by either paired or grouped $t$ test (24).

\section{RESULTS}

Uptake and excretion of bile salt by isolated perfused liver. The liver not only synthesizes bile salts but also efficiently removes them from blood and excretes them in bile. Thus, if the isolated liver is to be a useful system for the study of bile salt regulation of hepatic cholesterol synthesis, bile salts must be handled by it as they are in vivo. To assess the ability of isolated liver to ex-

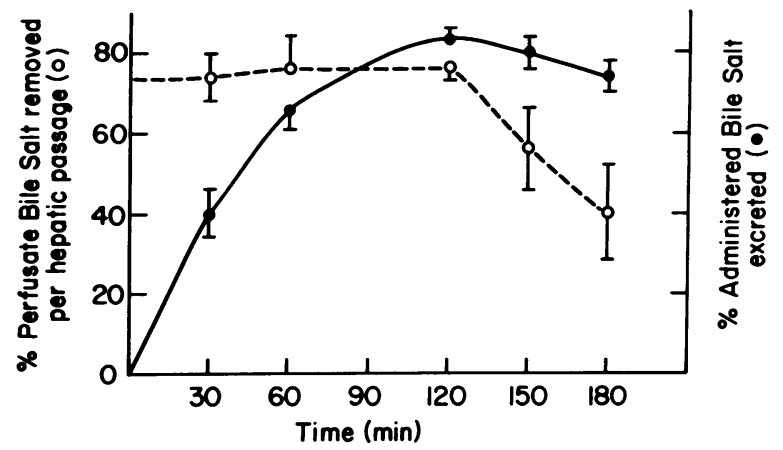

FIgURE 1 Uptake and excretion of bile salts by the isolated perfused liver. Livers were perfused in situ with a medium containing red blood cells, albumin, glucose, and Krebs bicarbonate buffer. $\left[{ }^{14} \mathrm{C}\right]$ Taurocholate was added continuously at the rate of $7 \mathrm{mg} / 100 \mathrm{~g}$ rat per h. Samples of perfusate were removed just before and just after passage through the liver and bile was collected via an indwelling bile duct cannula. The samples were assayed for radioactivity as described under Methods. Results are means $\pm \mathrm{SE} ; n=5$. tract and excrete bile salts, radiolabeled taurocholate was added continuously to the perfusate, at the rate of 7 $\mathrm{mg} / \mathrm{h}$ per $100 \mathrm{~g}$ rat. Samples of the portal and hepatic vein perfusate were assayed for radioactivity, and the percent of bile salt extracted per transhepatic passage was calculated. The results are shown in Fig. 1. The efficiency of bile salt extraction from perfusate was about $75 \%$ per passage during the first $2 \mathrm{~h}$ and then began to decline variably, falling to $54 \pm 10 \%$ at $2.5 \mathrm{~h}$ and $40 \pm 12 \%$ at $3 \mathrm{~h}$. The rate for the first $2 \mathrm{~h}$ approaches the $90 \%$ extraction rate reported for liver in vivo (25). The difference may be due to the higher perfusate flow rate used in isolated liver, which could result in solute streaming (26). Nevertheless, a steady-state perfusate concentration is quickly achieved, and since this concentration is higher than the normal portal venous bile salt concentration, the net bile salt extracted per passage is similar to that in vivo. The decrease in function that occurred between 2 and $3 \mathrm{~h}$ was variable and is consistent with other data ${ }^{2}$ (27) suggesting that $3 \mathrm{~h}$ of perfusion represents the upper limit of usefulness of this preparation.

To insure that the extracted bile salts behave analogously to bile salts in vivo, their rate of appearance in the bile produced by the isolated liver was measured. It is apparent from the data in Fig. 1 that they are excreted rapidly in bile and that the added bile salts efficiently traverse the hepatocyte with almost quantitative biliary excretion. This is similar to their metabolism in vivo. The fall of the percent of total administered bile salt excreted after $2.5 \mathrm{~h}$ was a function of the diminished bile flow, usually apparent during the last 30 min of the perfusion; this was not secondary to a decrease in the bile salt concentration of the bile.

Taken together, these data demonstrate that the transhepatic flux of bile salt in the isolated liver is qualitatively and quantitatively similar to that in vivo and provides support for the use of this system for the purposes outlined.

Effect of liver perfusion on hepatic HMG CoA reductase. The liver of rats sacrificed $3 \mathrm{~h}$ after the onset of the light phase of the diurnal cycle $(10$ a.m.) were perfused with a plasma-free buffer and the HMG CoA reductase activity of the liver was measured after 1,2 , or $3 \mathrm{~h}$ of perfusion. As shown in Fig. 2, enzyme activity doubled by $2 \mathrm{~h}$ and was three times the basal value after $3 \mathrm{~h}$ of perfusion. Activity fell after $4 \mathrm{~h}$ of perfusion, consistent with declining viability of the preparation (data not shown). Because the increase in activity was linear through the $3 \mathrm{rd} \mathrm{h}$, later studies compare the initial enzyme activity with the activity after $3 \mathrm{~h}$ of perfusion. Notably, this increase occurred during a period when

\footnotetext{
${ }^{3}$ Cooper, A. D. Unpublished data.
} 


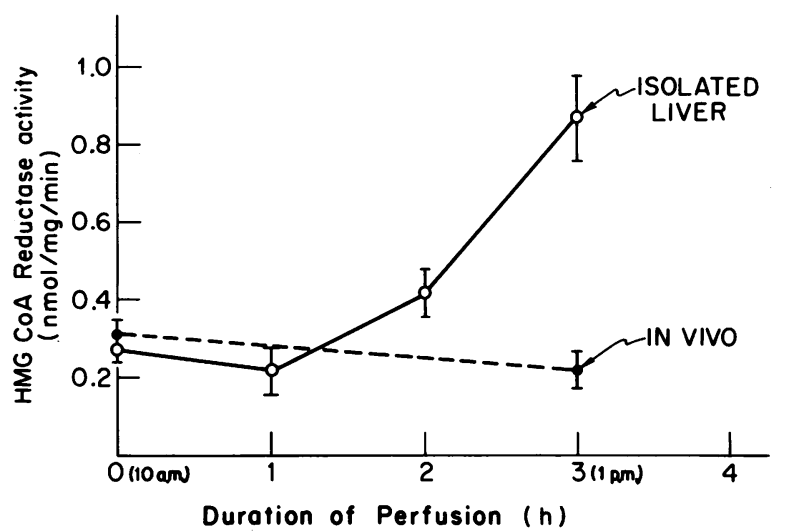

FIGURE 2 Effect of liver perfusion on hepatic HMG CoA reductase. $\mathrm{HMG} \mathrm{CoA}$ reductase activity was determined in liver before $(0)$ and after 1,2 , or $3 \mathrm{~h}$ of perfusion with the medium described in Fig. 1. Results are shown on the solid line. On the dotted line, the hepatic HMG CoA reductase activity of rats sacrificed at 10 a.m. and 1 p.m. is shown (in vivo). Results are means $\pm \mathrm{SE}, n=3$ except 0 -h $n=8$ and 3 -h isolated liver $n=5$.

little change in enzyme activity is seen in vivo (Fig. 2, dotted line).

The rise in enzyme activity was prevented by the addition of cycloheximide to the perfusate (Table II). These findings are consistent with the hypothesis (9, 10) that plasma contains a factor (s) that represses HMG CoA reductase activity by altering the rate of new enzyme synthesis.

Effect of bile salt addition on hepatic $H M G$ CoA reductase. To test the hypothesis that bile salts directly repress $\mathrm{HMG}$ CoA reductase activity (28), taurocholate was added continuously to the perfusate at a rate ap- proximating the normal bile salt return to the liver ( 8 $\mathrm{mg} / 100 \mathrm{~g}$ rat per $\mathrm{h}$ ) (12). After $3 \mathrm{~h}$ of perfusion with bile salt addition, there was no difference in the reductase activity of control perfused livers and those receiving bile salt infusion (Table II). Similar results (Table II) were obtained when taurochenodeoxycholate was infused at a rate chosen to approximate the rate of taurochenodeoxycholate flux through the enterohepatic circulation in rats fed $1 \%$ taurochenodeoxycholate diet for $1 \mathrm{w}$ (12). Furthermore, livers perfused with both taurocholate and taurochenodeoxycholate in relative concentrations similar to that of normal rat bile but infused at nearly twice the rate of basal bile flow showed results similar to those of control perfused livers (Table II). This high and unphysiologic rate was chosen to insure that transhepatic bile salt flux would be greater than normal. That this must be the case is apparent from the data in Fig. 2, where it is shown that $80 \%$ of infused bile salt has been excreted by $2.5 \mathrm{~h}$ so that the transhepatic flux was at least $11 \mathrm{mg} / \mathrm{h}$ per $100 \mathrm{~g}$ rat.

It can be seen from the results in Table II that both the absolute and relative change in enzyme activity during liver perfusion was of the same magnitude, whether bile salts had been added or not. These results clearly demonstrate that neither taurocholate nor taurochenodeoxycholate, over a range of physiologic and supraphysiologic flow rates, can prevent the increase in hepatic HMG CoA reductase induced by perfusion, when the liver is removed during a period of basal and normally constant enzyme activity.

Effect of cholcstcrol-enriched perfusate on hepatic H.MG CoA reductase. To study the effect of pure cholesterol on hepatic $\mathrm{HMG}$ CoA reductase, a choles-

TABLE II

Effect of Bile Salts and Protein Inhibitors on HMG CoA Reductase

\begin{tabular}{|c|c|c|c|c|}
\hline & \multicolumn{3}{|c|}{ HMG CoA reductase } & \multirow{2}{*}{$\frac{\text { Post-pre }}{\text { Pre }} \times 100$} \\
\hline & Pre & Post & Pre vs. post* & \\
\hline & \multicolumn{2}{|c|}{$\mathrm{nmol} / \mathrm{min} / \mathrm{mg} \times 10^{2}$} & $P<$ & mean \% change \\
\hline Plasma-free Perfusate $(n=5)$ & $27 \pm 4$ & $87 \pm 11$ & 0.005 & $227 \pm 41$ \\
\hline Cycloheximide $(0.1 \mathrm{mM})(n=3)$ & $18 \pm 3$ & $27 \pm 2 \ddagger$ & NS & $48 \pm 13 \ddagger$ \\
\hline Cycloheximide $(0.2 \mathrm{mM})(n=2)$ & 20 & 27 & NS & $31 \S$ \\
\hline Taurocholate $(8.5 \mathrm{mg} / 100 \mathrm{~g}$ rat $/ \mathrm{h})(n=4)$ & $27 \pm 7$ & $75 \pm 14$ & 0.02 & $209 \pm 53$ \\
\hline$(12.5 \mathrm{mg} / 100 \mathrm{~g} \mathrm{rat} / \mathrm{h})(n=5)$ & $28 \pm 4$ & $81 \pm 7$ & 0.001 & $219 \pm 57$ \\
\hline $\begin{array}{l}\text { Taurocholate }+ \text { taurochenodeoxycholate } \\
\quad(12 \mathrm{mg}+3 \mathrm{mg} / 100 \mathrm{~g} \text { rat } / \mathrm{h})(n=4)\end{array}$ & $31 \pm 6$ & $83 \pm 10$ & 0.005 & $286 \pm 22$ \\
\hline
\end{tabular}

HMG CoA reductase activity was determined in samples of the same liver before and after liver perfusion. Perfusate is described in Fig. 1. Bile salts were added continuously at rate specified or cycloheximide was added in the concentration specified. Means $\pm S E$.

* Paired $t$ test; NS, not significant.

$\ddagger$ Differs significantly from plasma-free perfusate, $P<0.01$ (group $t$ test).

$\S$ Differs significantly from plasma-free perfusate, $P<0.05$ (group $t$ test). 
TABLE III

Effect of Cholesterol-Enriched Perfusate on $H M G$ CoA Reductase

\begin{tabular}{ccc}
\hline & \multicolumn{2}{c}{ HMG CoA reductase } \\
\cline { 2 - 3 } Perfusate & Pre & Post \\
\hline & \multicolumn{2}{c}{$n$ mol $/ m i n / m g \times 10^{2}$} \\
$\begin{array}{l}\text { Plasma-free }(n=5) \\
\text { Cholesterol-enriched } \\
\quad(20 \mathrm{mg} / 100 \mathrm{ml})(n=4)\end{array}$ & $37 \pm 11$ & $87 \pm 11$ \\
$\begin{array}{c}\text { Cholesterol-enriched } \\
\quad+\text { taurocholate } \\
\quad(10 \mathrm{mg} / 100 \mathrm{~g} \text { rat } / \mathrm{h})(n=4)\end{array}$ & $18 \pm 8$ & $29 \pm 8^{*}$ \\
$\begin{array}{l}\text { Cholesterol-enriched } \\
+ \text { taurochenodeoxycholate } \\
\quad(10 \mathrm{mg} / 100 \mathrm{~g} \text { rat } / \mathrm{h})(n=4)\end{array}$ & $34 \pm 13$ & $43 \pm 13 \ddagger$ \\
\hline
\end{tabular}

HMG CoA reductase actiyity was determined in samples of the same liver before and after a 3-h perfusion. Perfusate composition was as described in Fig. 1 (plasma-free perfusate) or contained a cholesterol lecithin dispersion (1:1 molar ratio) (cholesterol-enriched). Bile salts were added continuously as described in Table II. Mean \pm SE.

* Significantly different from plasma-free perfusate, $P<0.01$. $\ddagger$ Significantly different from plasma-free perfusate, $P<0.05$.

terol: lecithin dispersion (1:1 molar ratio) was added to the perfusate, resulting in a final perfusate cholesterol concentration $(20 \mathrm{mg} / 100 \mathrm{ml}$ ) comparable to the serumfree cholesterol concentration of normal rat blood. As shown in Table III, perfusate containing cholesterol completely prevented the increase in $\mathrm{HMG}$ CoA reductase activity seen with cholesterol-free perfusion of liver during the basal period. To explore the possibility that bile salts might have an additive effect with cholesterol, taurocholate or taurochenodeoxycholate was infused continuously into cholesterol-enriched perfusate.

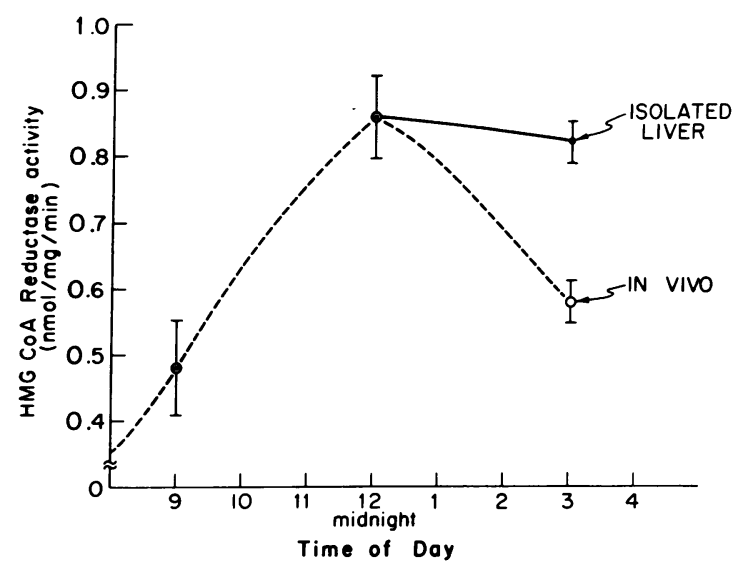

Figure 3 Effect of perfusion at the peak of the diurnal cycle on HMr CoA reductase. The procedure described in Table II for the plasma-free perfusate was used, except the perfusions were begun at the middle of the dark phase (midnight). Means $\pm \mathrm{SE} ; n=4$.

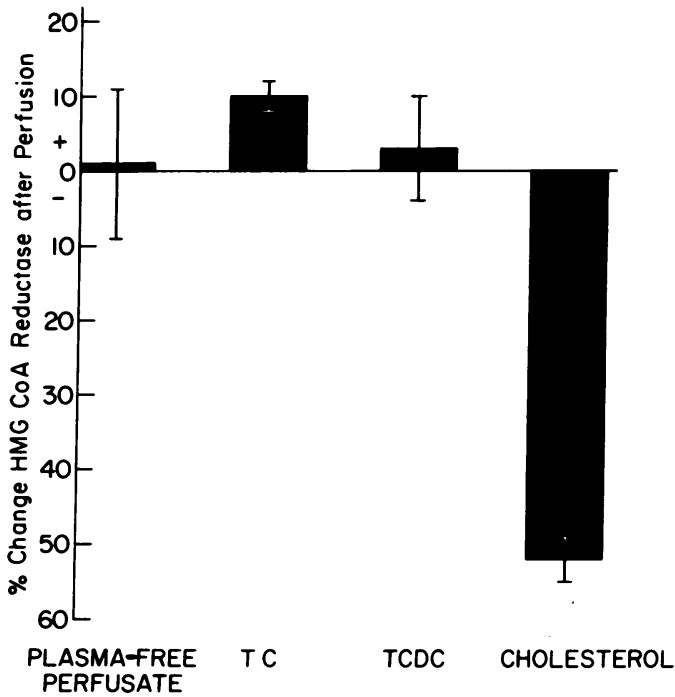

FIGURE 4 The effect of bile salt and cholesterol at the peak of the diurnal cycle. HMG CoA reductase was determined before and after a 3-h perfusion of liver isolated at the middle of the dark period. The perfusate is described in Fig. 1. Taurocholate (TC) was added continuously at the rate of $8.5 \mathrm{mg} / 100 \mathrm{~g}$ rat per $\mathrm{h}$. Taurochenodeoxycholate (TCDC) was added continuously at a rate of $12.5 \mathrm{mg} / 100$ $\mathrm{g}$ rat per $\mathrm{h}$. Cholesterol was added as described in Table III. Percent change was calculated as in Table II. Only in the cholesterol-perfused liver was the change in reductase during perfusion significant, $P<0.02$. Means \pm SE; $n=4$.

As shown in Table III, bile salt addition again had no effect on HMG CoA reductase activity.

These results demonstrate that HMG CoA reductase activity of isolated liver is subject to regulation by the perfusate content, substantiating the usefulness of this model for the study of hepatic cholesterol synthesis. Moreover, they show that pure cholesterol, in the absence of associated sterols or lipoproteins, is capable of altering the activity of hepatic $\mathrm{HMG}$ CoA reductase in the intact isolated liver.

HMG CoA reductase regulation in liver isolated at the middle of the dark phase. Cholesterol synthesis and HMG CoA reductase activity varies with the time of day and reaches a peak at the middle of the dark period (midnight) (29). Since bile salt regulation of cholesterol synthesis has been reported to be most pronounced during the dark period (28), rat livers were isolated at the midpoint of the dark phase and perfused with the plasma-free perfusate. In contrast to the results obtained with livers from the basal period, enzyme activity was essentially unchanged during a 3 -h perfusion (Fig. 3, solid line). However, since enzyme activity decreases in vivo during this period (Fig. 3 , dotted line), this response also suggests that plasma-free perfusate lacks an inhibitor of HMG CoA reductase activity. 
When bile salts were added to the perfusate during the dark period, no inhibition of $\mathrm{HMG}$ CoA reductase activity occurred (Fig. 4). This was true both for taurocholate and taurochenodeoxycholate infused at basal and suprabasal rates. In contrast, if the perfusate was enriched with cholesterol, the HMG CoA reductase activity declined by $52 \pm 4 \%$ (Fig. 4 ). This is a change of the same magnitude as occurs in vivo during this period (Fig. 3). Moreover, since the reported half-life of the enzyme is about $3 \mathrm{~h}(30,31)$, this is the maximum decline one would expect if cholesterol addition completely inhibited the synthesis of HMG CoA reductase without changing the degradation rate of the enzyme.

Effect of perfusion with blood-containing buffer. While the use of a plasma-free perfusate affords control of its composition, such perfusates are less effective in maintaining liver viability for longer perfusions. However, perfusates containing whole rat blood maintain liver viability for longer periods but suffer the disadvantage of having numerous constituents whose concentrations may change during the course of an experiment (32). Although it is extremely unlikely that our results could have been secondary to decreasing viability of the liver during the later portion of the perfusion, a series of experiments were undertaken with whole rat blood, diluted (1:1, vol: vol) with Krebs bicarbonate buffer, as the perfusate. Both taurocholate and taurochenodeoxycholate were infused at basal bile salt flux rates and at twice the basal rate. Perfusion invariably induced a rise in $\mathrm{HMG}$ CoA reductase, which was neither prevented nor modified by the addition of bile salts to the perfusate (Table IV).

TABLE IV

Effect of Perfusion with Plasma-Containing Buffer

\begin{tabular}{|c|c|c|c|}
\hline & \multicolumn{2}{|c|}{ HMG CoA reductase } & \multirow{2}{*}{$\frac{\text { Post-pre }}{\text { pre }} \times 100$} \\
\hline & Pre & Post & \\
\hline & \multicolumn{2}{|c|}{$\mathrm{nmol} / \mathrm{min} / \mathrm{mg} \times 10^{2}$} & mean \% change \\
\hline $\begin{array}{l}\text { Control } \\
\text { Taurocholate }\end{array}$ & $36 \pm 5$ & $68 \pm 16^{*}$ & $88 \pm 27$ \\
\hline $\begin{array}{r}7 \mathrm{mg} / 100 \mathrm{~g} \mathrm{rat} / \mathrm{h} \\
14 \mathrm{mg} / 100 \mathrm{~g} \mathrm{rat} / \mathrm{h}\end{array}$ & $\begin{array}{l}20 \pm 4 \\
23 \pm 3\end{array}$ & $\begin{array}{l}67 \pm 12 \ddagger \\
55 \pm 4^{*}\end{array}$ & $\begin{array}{l}267 \pm 115 \\
146 \pm 34\end{array}$ \\
\hline $\begin{array}{l}\text { Taurochenodeoxychola } \\
7 \mathrm{mg} / 100 \mathrm{~g} \mathrm{rat} / \mathrm{h} \\
14 \mathrm{mg} / 100 \mathrm{~g} \mathrm{rat} / \mathrm{h}\end{array}$ & $\begin{array}{l}32 \pm 7 \\
24 \pm 4\end{array}$ & $\begin{array}{l}57 \pm 5 \ddagger \\
51 \pm 6 \ddagger\end{array}$ & $\begin{array}{r}84 \pm 24 \\
110 \pm 14\end{array}$ \\
\hline
\end{tabular}

HMG CoA reductase activity was determined before and after a 3-h perfusion. The perfusate contained $50 \%$ whole rat blood and $50 \%$ Krebs bicarbonate buffer (control) and had a cholesterol content of $22 \pm 5 \mathrm{mg} / 100 \mathrm{ml}$ supernate. Bile salts were added to this perfusate at the indicated rates. Mean $\pm \mathrm{SE}$, $n=3$.

* Post differs significantly from pre, $P<0.05$.

$\ddagger$ Post differs significantly from pre, $P<0.02$.
TABLE V

Hepatic Cholesterol Content

\begin{tabular}{lc}
\hline & Cholesterol \\
\hline & $\mu g /$ mg protein \\
Unperfused $(n=6)$ & $11.6 \pm 0.5$ \\
Control perfusate $(n=10)$ & $10.4 \pm 0.4^{*}$ \\
Cholesterol-enriched perfusate $(n=9)$ & $11.6 \pm 0.6 \ddagger$ \\
Bile salt-enriched perfusate $(n=6)$ & $10.4 \pm 0.3$
\end{tabular}

The hepatic cholesterol content was determined in unperfused liver and in liver after perfusion with various buffers. It is expressed as micrograms cholesterol per milligram protein to eliminate the potential effect of liver perfusion on hepatic weight.

* Differs significantly from unperfused liver, $P<0.02$.

$\ddagger$ Differs significantly from liver perfused without cholesterol, $P<0.05$.

Notably, the magnitude of the increase with perfusion in this series of experiments is somewhat less than that in comparable groups of livers perfused with plasma-free medium ( Table II). This is not surprising since plasma contains cholesterol, which should inhibit the enzyme activity. That this effect is not more pronounced could be due either to the presence of hormonal stimulators of $\mathrm{HMG} \mathrm{CoA}$ reductase or to inefficient uptake of lipoprotein cholesterol by the isolated liver.

Since bile salts are also ineffective in altering HMG CoA reductase activity in the more physiologic milieu afforded by a whole-blood perfusate, these results strengthen the conclusion that bile salts are not direct regulators of hepatic cholesterol synthesis.

Effect of liver perfusion on hepatic cholesterol content. The total cholesterol content of unperfused liver and of liver subjected to a variety of perfusates is shown in Table V. Perfusion with the control buffer resulted in a small but significant decrease in the hepatic total cholesterol content (Table V), probably the result of cholesterol excretion, both via lipoproteins and bile. The addition of cholesterol to the perfusate prevented this decrease (Table $\mathrm{V}$ ). If this decrease in hepatic cholesterol content was the cause of the increase in $\mathrm{HMG}$ CoA reductase activity, the liver is very sensitive to this stimulus, since the cholesterol content fell less than $10 \%$ after $3 \mathrm{~h}$ of perfusion.

\section{DISCUSSION}

In 1950 Gould and Taylor (33) reported that cholesterol feeding resulted in decreased hepatic cholesterol synthesis. Subsequently, research has estabilshed that cholesterol from intestine, carried in chylomicrons, is removed from the circulation by the liver (34). This results in an increase in the hepatic content of esterified cholesterol accompanied by a fall in hepatic cholesterol synthetic rate $(35)$.

\section{6 A. D. Cooper}


The intracellular events that lead to the decreased rate of synthesis are incompletely understood. It has been established that under most circumstances the overall rate of hepatic cholesterol synthesis is controlled by the rate of reductive deacylation of $\mathrm{HMG} \mathrm{CoA}$ to form mevalonic acid by the enzyme $\mathrm{HMG}$ CoA reductase (36). In general, this enzyme's activity is proportional to the quantity of enzyme present and this is determined primarily by changes in the rate of enzyme synthesis (31). Recent evidence suggests that inactivation of the enzyme by proteins (37), sterols (38), and ATP (39) may also occur. Kandutsch and Chen $(40,41)$ have suggested that cholesterol itself does not regulate the activity of HMG CoA reductase but that certain oxygenated or hydroxylated degradation products of cholesterol are the active regulators.

The role of bile salts in this process is unclear. The report of Beher and Baker (3), followed by numerous confirmations, has established that chronic bile salt feeding reduces the rate of hepatic cholesterol synthesis. However, bile salt feeding also increases the rate of cholesterol absorption (42), decreases the rate of cholesterol catabolism to bile salt (43), and increases the rate of cholesterol excretion (44). The net result is almost always an increase in hepatic or serum cholesterol content or both (45). Moreover, after bile duct obstruction, the rate of cholesterol synthesis increases (46), despite an increase in hepatic bile salt content (47). Thus, the bile salt effect could well be mediated by the other changes in cholesterol metabolism. Although experimental confirmation is lacking, the hypothesis that bile salts, especially chenodeoxycholate, are direct regulators of $\mathrm{HMG} \mathrm{CoA}$ reductase has been evoked to explain the effect of bile salt feeding on cholesterol synthesis and bile composition (12). This question is of timely interest because of the recent use of chenodeoxycholate for the dissolution of gallstones (11).

Attempts to evaluate the ability of bile salts to act as independent regulators of hepatic cholesterol synthesis in rats in vivo have led to contradictory conclusions. Weis and Dietschy (48) diverted the bile of rats and thus eliminated both bile salt and cholesterol absorption. They then replaced either bile salts or chylomicrons containing cholesterol and found that bile salts could not reduce hepatic cholesterol synthesis but the cholesterol preparation could. Hamprecht et al. (28) diverted the lymph and hence any absorption of cholesterol, and fed bile salts to these rats. They found that cholic acid feeding under these circumstances was effective in reducing the level of hepatic HMG CoA reductase. Shefer and associates (12), using a variety of bile salts and dietary manipulations in long-term feeding experiments, tentatively concluded that taurochenodeoxycholate rather than taurocholate might have a direct effect on hepatic
HMG CoA reductase in the rat. No explanation is readily available for the discrepancies in the conclusions reached in these reports.

Because of the difficulties involved in trying to control all of the interrelationships between cholesterol and bile salt metabolism in vivo, it is apparent that isolated cell or organ systems are necessary to answer this question. Previous work with in vitro systems has been incomplete. It has been reported that bile salts do not alter the rate of hepatic cholesterol synthesis or HMG CoA reductase activity when incorporated in the medium used to culture human (9) or mouse fibroblasts (40), fetal mouse liver cells (48), or adult rat hepatocytes. ${ }^{3}$ Because it allows the investigator to control the composition of the blood reaching the liver, the isolated perfused liver appears to be an excellent system in which to resolve this question. This system first used by Liersch et al. (13), who added cholate and taurocholate to a hemoglobin-free liver perfusate and found that they did not alter the rate of ${ }^{3} \mathrm{H}_{2} \mathrm{O}$ incorporation into cholesterol, despite infusions of up to 3 h. Thus, their work provides strong evidence that cholate at physiologic portal vein concentrations is not a repressor of hepatic cholesterol synthesis. The results of our investigation, which confirm and extend those of Liersch et al. (13), contribute additional strong support for the concept that the major bile salts per se are not capable of directly regulating the activity of hepatic microsomal HMG CoA reductase and, hence, hepatic cholesterol synthesis under circumstances where cholesterol itself has such an effect.

In our experiments, the isolated perfused rat liver was also utilized as a model system. The advantage of this approach was that it provided almost complete control of the composition of the hepatic inflow, as well as control of the quantity of bile salt being transported from the perfusate, through the hepatocyte, into the bile. Moreover, because of the short half-life of the enzyme HMG CoA reductase $(30,31)$, significant changes in its activity can be measured within the period of the liver's viability. Neither taurocholate nor taurochenodeoxycholate, alone or in combination, could affect the activity of $\mathrm{HMG}$ CoA reductase, despite infusion at a variety of rates, both physiologic and supraphysiologic. The latter rates were chosen to insure that the amount of bile salts traversing the hepatocytes would be greater than in the normal liver, and in some instances would be in the range achieved with chronic bile salt feeding. In addition, because of the known diurnal variation in the rate of hepatic cholesterol synthesis (29), experiments were carried out in livers isolated both at the height and at the nadir of this circadian rhythm. Although hepatic HMG CoA reductase responds somewhat differently to

${ }^{3}$ Bissell, D. M. Personal communication. 
perfusion at these time periods, no effect of bile salt on enzyme activity was discerned in either group of experiments. Finally, to insure that the lack of bile salt effect was not the result of the perfusate composition, experiments were carried out with a plasma-free-cholesterol-poor perfusate, a plasma-free-cholesterol-enriched perfusate, and a plasma-containing perfusate. Again, although hepatic HMG CoA reductase responds differently to these perfusates, no effect attributable to bile salt addition occurred. The possibility that a primary or secondary bile salt ordinarily present in trace amounts in the bile is a regulator of cholesterol synthesis is not excluded by these data. We must conclude, however, that neither taurocholate nor taurochenodeoxycholate is a direct regulator of hepatic $\mathrm{HMG} \mathrm{CoA}$ reductase and that the effect of bile salt feeding on hepatic cholesterol synthesis seems to be mediated by another effect of bile salt on hepatic cholesterol metabolism.

The finding that small changes in hepatic cholesterol content occur reciprocally with change in cholesterol synthesis suggests that these changes (49) or perhaps the cholesterol content of some intracellular compartment (50) may ultimately mediate the bile salt effect. That this was not noted in all studies of bile salt feeding (12) may be due to the fact that a large number of animals must be studied before such small changes become statistically significant. Moreover, in chronic feeding experiments, sufficient time may elapse before the measurement of cholesterol content to allow a return to homeostasis with the achievement of near-normal hepatic cholesterol levels $(12,51)$.

It is also clear from our results that highly purified cholesterol, in the absence of significant amounts of other sterols or lipoproteins, is capable of suppressing hepatic $\mathrm{HMG}$ CoA reductase activity. While this does not by any means establish that the infused cholesterol itself is the final mediator, it does indicate that cholesterol alone is sufficient to initiate the chain of events leading to the inhibition of hepatic cholesterol synthesis.

The difference in response of hepatic HMG CoA reductase to perfusion with plasma-free and whole-bloodcontaining buffers is of note. That perfusion of isolated liver with a plasma-free medium results in an increase of hepatic cholesterol synthesis is not surprising in light of the findings of others. It is probable that this response in isolated liver is similar to the stimulation of HMG CoA reductase that occurs when fibroblasts (9), hepatoma cells (10), or rat hepatocytes (52) are cultured in plasma-free medium. However, in contrast to these isolated cell systems, the addition of whole plasma to the perfusate only partially prevented the stimulation. This suggests that the inhibitory factor in plasma is present in limited quantity and may require the presence of peripheral tissues for its activation or continuous sup- ply. This speculation is consistent with our current understanding of chylomicron metabolism (53).

The different response of liver to perfusion at the height and at the nadir of the diurnal cycle of cholesterol synthesis was of note. Perfusion of liver isolated at the basal period of synthetic activity results in an increase in enzyme activity, and the inclusion of inhibitors of protein synthesis or of HMG CoA reductase, such as cycloheximide or cholesterol, prevents this rise. However, neither inhibitor was able to cause a reduction of HMG CoA reductase activity below the initial level. In contrast, liver perfused at the height of the circadian rhythm of synthetic activity did not respond with an increase in $\mathrm{HMG}$ CoA reductase activity. Rather, the already high level of enzyme activity was maintained when it would otherwise have begun to decrease. The presence of cholesterol at this time caused a marked fall in enzyme activity and the magnitude of decrease was consistent with the rate of decline of activity expected with the cessation of new enzyme synthesis. These results raise the possibility that different systems of control of enzyme activity may be operative during these different periods in the circadian rhythm.

\section{ACKNOWLEDGMENTS}

I wish to thank A. Garst and K. Leu for expert technical assistance and Drs. R. Gordon Gould and Gary M. Gray for many helpful discussions during the course of this work and the preparation of the manuscript.

This work was supported by grants from the National Institutes of Health (AM 18774) and the American Cancer Society.

\section{REFERENCES}

1. Cooper, A. D., and S. K. Leu. 1975. Failure of bile salt to regulate $\beta$-hydroxy- $\beta$-methylglutaryl CoA reductase in the isolated perfused liver. Clin. Res. 23: 248A. (Abstr.).

2. Bortz, W. M. 1973. On the control of cholesterol synthesis. Metab. Clin. Exp. 22: 1507-1524.

3. Beher, W. T., and G. D. Baker. 1958. Effect of dietary bile acids on in viz'o cholesterol metabolism in the rat. Proc. Soc. Exp. Biol. Med. 98: 892-894.

4. Wilson, J. D. 1972. The role of bile acids in the overall regulation of steroid metabolism. Arch. Intern. Med. 130: 493-505.

5. Dietschy, J. M., and J. D. McGarry. 1974. Limitations of acetate as a substrate for measuring cholesterol synthesis in liver. J. Biol. Chem. 249: 52-58.

6. Windmueller, H. G., and A. E. Spaeth. 1966. Perfusion in situ with tritium oxide to measure hepatic lipogenesis and lipid secretion. Normal and orotic-fed rats. J. Biol. Chem. 241: 2891-2899.

7. Linn, T. C. 1967. The demonstration and solubilization of $\beta$-hydroxy- $\beta$-methylglutaryl coenzyme A reductase from rat liver microsomes. J. Biol. Chem. 242: 984-989.

8. Dietschy, J. M., and M. S. Brown. 1974. Effect of alterations of the specific activity of the intracellular acetyl CoA pool on apparent rates of hepatic cholesterogenesis. J. Lipid Res. 15: 508-516.

\section{8


9. Brown, M. S., S. E. Dana, and J. L. Goldstein. 1974. Regulation of 3-hydroxy-3-methylglutaryl coenzyme A reductase activity in cultured human fibroblasts. Comparison of cells from a normal subject and from a patient with homozygous familial hypercholesterolemia. J. Biol. Chem. 249: 789-796.

10. Kirsten, E. S., and J. A. Watson. 1974. Regulation of 3-hydroxy-3-methylglutaryl coenzyme A reductase in hepatoma tissue culture cells by serum lipoproteins. $J$. Biol. Chem. 249: 6104-6109.

11. Danzinger, R. G., A. F. Hofmann, L. J. Schoenfield, and J. L. Thistle. 1972. Dissolution of cholesterol gallstones by chenodeoxycholic acid. N. Engl. J. Med. 286: 1-8.

12. Shefer, S., S. Hauser, V. Lapar, and E. H. Mosbach. 1973. Regulatory effects of sterols and bile acids on hepatic 3-hydroxy-3-methylglutaryl CoA reductase and cholesterol $7 \alpha$-hydroxylase in the rat. J. Lipid Res. 14: 573-580.

13. Liersch, M. E. A., C. A. Barth, H. J. Hackenschmidt, H. L. Ullmann, and K. F. A. Decker. 1973. Influence of bile salts on cholesterol synthesis in the isolated perfused rat liver. Eur. J. Biochem. 32: 365-371.

14. Pope, J. L. 1967. Crystallization of sodium taurocholate. J. Lipid Res. 8: 146-147.

15. Goldfarb, S., and H. C. Pitot. 1971. Improved assay of 3-hydroxy-3-methylglutaryl coenzyme A reductase. $J$. Lipid Res. 12: 512-515.

16. Mortimore, G. E. 1961. Effect of insulin on potassium transfer in isolated rat liver. Am. J. Phy'siol. 200: 13151319.

17. Hamilton, R. L., M. N. Berry, M. C. Williams, and E. M. Severinghaus. 1974. A simple and inexpensive membrane "lung" for small organ perfusion. J. Lipid Res. 15 : 182-186.

18. Rodwell, V. W., D. J. McNamara, and D. J. Shapiro 1973. Regulation of hepatic 3-hydroxy-3-methylglutarylcoenzyme A reductase. Adv. Enzymol. Relat. Areas Mol. Biol. 38: 373-412.

19. Barth, C., M. Liersch, J. Hackenschmidt, H. Ullmann, and K. Decker. 1972. Cholesterol biosynthesis in the isolated perfused rat liver. Hoppe Seylers Z. Physiol. Chem. 353 : 1085-1093.

20. Cooper, R. A., E. C. Arner, J. S. Wiley, and S. J. Shattil. 1975. Modification of red cell membrane structure by cholesterol-rich lipid dispersions. A model for the primary spur cell defect. J. Clin. Invest. 55: 115126.

21. Folch, J., M. Lees, and G. H. Sloane-Stanley. 1957. A simple method for the isolation and purification of total lipides from animal tissues. J. Biol. Chem. 226: 497-509.

22. Zlatkis, A., B. Zak, and A. J. Boyle. 1953. A new method for the direct determination of serum cholesterol. J. Lab. Clin. Med. 41: 486-492.

23. Lowry, O. H., N. J. Rosebrough, A. L. Farr, and R. J. Randall. 1951. Protein measurement with the Folin phenol reagent. J. Biol. Chem. 193: 265-275.

24. Snedecor, G. W., and W. G. Cochran. 1967. Statistical Methods, Iowa State University Press, Ames, Iowa. 593 pp.

25. O'Máille, E. R. L., T. G. Richards, and A. H. Short. 1967. The influence of conjugation of cholic acid on its uptake and secretion: hepatic extraction of taurocholate and cholate in the dog. J. Physiol. (Lond.). 189: 337350 .
26. Goresky, C. A. 1964. Initial distribution and rate of uptake of sulfbromophthaline in the liver. Am. J. Physiol. 207: 13-26.

27. Bartosek, I., A. Guaitani, and S. Garattini. 1973. Prolonged perfusion of isolated rat liver. In Isolated Liver Perfusion and Its Applications. I. Bartosek, A. Guatani, and L. L. Miller, editors. Raven Press, New York. 63-72.

28. Hamprecht, B., R. Roscher, G. Waltinger, and C. Nïssler. 1971. Influence of bile acids on the activity of rat liver 3-hydroxy-3-methylglutaryl coenzyme A reductase. 2. Effect of cholic acid in lymph fistula rats. Eur. J. Biochem. 18: 15-19.

29. Back, P., B. Hamprecht, and F. Lynen. 1969. Regulation of cholesterol biosynthesis in rat liver: diurnal changes of activity and influence of bile acids. Arch. Biochem. Biophy's. 133: 11-21.

30. Edwards, P. A., and R. G. Gould. 1972. Turnover rate of hepatic 3-hydroxy-3-methylglutaryl coenzyme A reductase $\mathrm{A}$ as determined by use of cycloheximide. $J$. Biol. Chem. 247 : 1520-1524.

31. Higgins, M., T. Kawachi, and H. Rudney. 1971. The mechanism of the diurnal variation of hepatic HMG$\mathrm{CoA}$ reductase activity in the rat. Biochem. Biophy's. Res. Commun. 45 : 138-144.

32. Exton, J. H. 1975. The perfused rat liver. Methods Enzymol. 39: 25-36.

33. Gould, R. G., and C. B. Taylor. 1950. Effect of dietary cholesterol on hepatic cholesterol synthesis. Fed. Proc. 9: 179. (Abstr.)

34. Quarfordt, S. H., and D. S. Goodman. 1967. Metabolism of doubly-labeled chylomicron cholesteryl esters in the rat. J. Lipid Res. 8: 264-273.

35. Nervi, F. O., H. J. Weis, and J. M. Dietschy. 1975. The kinetic characteristics of inhibition of hepatic cholesterogenesis by lipoproteins of intestinal origin. J. Biol. Chem. 250: 4145-4151.

36. Siperstein, M. D., and V. M. Fagan. 1966. Feedback control of mevalonate synthesis by dietary cholesterol. J. Biol. Chem. 241: 602-609.

37. McNamara, D. J., and V. W. Rodwell. 1975. Regulation of hepatic 3-hydroxy-3 methylglutaryl coenzyme A reductase. In vitro inhibition by a protein present in bile. Arch. Biochem. Biophl's. 168: 378-385.

38. Higgins, M., and H. Rudney. 1973. Regulation of rat liver $\beta$-hydroxy- $\beta$-methylglutaryl CoA reductase activity by cholesterol. Nat. New Biol. 246: 60-61.

39. Chow, J. C., M. J. P. Higgins, and H. Rudney. 1975. The inhibitory effect of ATP on HMG-CoA reductase. Biochem. Biophy's. Res. Commun. 63: 1077-1084.

40. Kandutsch, A. A., and H. W. Chen. 1972. Inhibition of sterol synthesis in cultured mouse cells by $7 \alpha$-hydroxycholesterol, $7 \beta$-hydroxycholesterol and 7-ketocholesterol. J. Biol. Chem. 248: 8408-8417.

41. Kandutsch, A. A., and H. W. Chen. 1974. Inhibition of sterol synthesis in cultured mouse cells by cholesterol derivatives oxygenated in the side chain. J. Biol. Chem. 249: 6057-6061.

42. Gallo-Torres, H. E., O. N. Miller, and J. G. Hamilton. 1969. A comparison of the effects of bile salts on the absorption of cholesterol from the intestine of the rat. Biochim. Biophys. Acta. 176: 605-615.

43. Bergström, S., and H. Danielsson. 1958. On the regulation of bile acid formation in the rat liver. Acta Physiol. Scand. 43: 1-7. 
44. Wheeler, H. O., and K. K. King. 1972. Biliary excretion of lecithin and cholesterol in the dog. J. Clin. Invest. 51 : 1337-1350.

45. Beher, W. T., G. D. Baker, and D. G. Penney. 1963. A comparative study of the effects of bile acid and cholesterol on cholesterol metabolism in the mouse, rat, hamster, and guinea pig. J. Nutr. 79: 523-530.

46. Cooper, A. D., and R. K. Ockner. 1974. Studies of hepatic cholesterol synthesis in experimental acute biliary obstruction. Gastroenterology. 66: 586-595.

47. Adler, R. D., and R. K. Ockner. 1974. Bile acid (BA) metabolism in selective biliary obstruction (SBO). Gastroenterology. 67: 778. (Abstr.)

48. Weis, H. J., and J. M. Dietschy. 1969. Failure of bile acids to control hepatic cholesterogenesis: evidence for endogenous cholesterol feedback. J. Clin. Invest. 48: 2398-2408.

49. Gould, R. G., V. B. Kojola, and E. A. Swyryd. 1970. Effects of hypophysectomy, adrenalectomy, cholesterol feeding, and puromycin on the radiation-induced increase in hepatic cholesterol biosynthesis in rats. Radiat. Res. 41: 57-69.

50. Harry, D. S., M. Dini, and N. McIntyre. 1973. Effects of cholesterol feeding and biliary obstruction on hepatic cholesterol synthesis in the rat. Biochim. Biophys. Acta. 296: 209-220.

51. Raicht, R. F., B. I. Cohen, and E. H. Mosbach. 1974. Effects of sodium taurochenodeoxycholate and sodium taurocholate on cholesterol absorption in the rat. Gastroenterology. 67 : 1155-1161.

52. Edwards, P. A. 1975. Effect of plasma lipoproteins and lecithin-cholesterol dispersions on the activity of 3-hydroxy-3-methylglutaryl-coenzyme A reductase of isolated rat hepatocytes. Biochim. Biophys. Acta. 409: 39-50.

53. Redgrave, T. G. 1970. Formation of cholesteryl esterrich particulate lipid during metabolism of chylomicrons. J. Clin. Invest. 49: 465-471. 